\begin{tabular}{|c|c|c|c|c|c|c|}
\hline \multirow{4}{*}{ Impact Factor: } & ISRA (India) & $=3.117$ & SIS (USA) & $=0.912$ & ICV (Poland) & $=6.630$ \\
\hline & ISI (Dubai, UAE & $=0.829$ & РИНЦ (Russia) & $=0.156$ & PIF (India) & $=1.940$ \\
\hline & GIF (Australia) & $=0.564$ & ESJI (KZ) & $=8.716$ & IBI (India) & $=4.260$ \\
\hline & JIF & $=1.500$ & SJIF (Morocco) & $=5.667$ & OAJI (USA) & $=0.350$ \\
\hline
\end{tabular}

\section{SOI: $1.1 /$ TAS $\quad$ DOI: $10.15863 /$ TAS \\ International Scientific Journal Theoretical \& Applied Science}

p-ISSN: 2308-4944 (print) e-ISSN: 2409-0085 (online)

Year: 2019 Issue: $07 \quad$ Volume: 75

Published: $29.07 .2019 \quad$ http://T-Science.org
QR - Issue

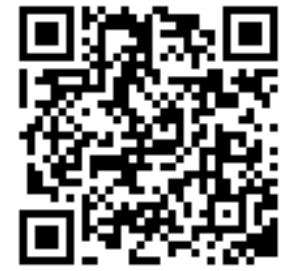

QR - Article

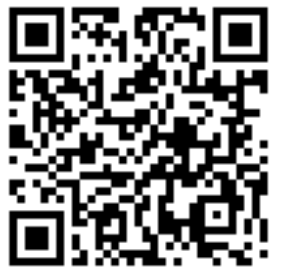

Nadir Ramazanov

Tashkent Regional State Pedagogical Institute Teacher of Uzbek Language and Literature Department dokma@bk.ru

\title{
THE POETIC INTERPRETATION OF THE CONCEPT FAQR IN THE LYRICS OF ALISHER NAVOI
}

Abstract: In this article, the interpretation of the concept of faqr in the lyrics of Alisher Navoi is analyzed from the point of view of poetic functionality. On the basis of the factual material, the place of the concept of faqr is revealed in the acquisition of the philosophical coloring of the spiritual world of lyrical images.

Key words: Alisher Navoi, lyrics, concepts of Sufism, faqr, Sufism and art Literature.

Language: Russian

Citation: Ramazanov, N. (2019). The poetic interpretation of the concept faqr in the lyrics of Alisher Navoi. ISJ Theoretical \& Applied Science, 07 (75), 344-347.

Soi: http://s-o-i.org/1.1/TAS-07-75-55 Doi: crossef https://dx.doi.org/10.15863/TAS.2019.07.75.55

Classifiers: Literature. Folklore. Translation Studies.

\section{ПОЭТИЧЕСКАЯ ИНТЕРПРЕТАЦИЯ КОНЦЕПТА ФАКР В ЛИРИКЕ АЛИШЕРА НАВОИ}

Аннотация: В этой статье интерпретация конщепта факр в лирике Алишера Навои анализировано с точки зрения поэтической функичиональности. На основе фактологического материала раскрыто место понятия факр в обретении философской окраски духовного мира лирических образов.

Ключевые слова: Алишер Навои, лирика, концепты суфизма, факр, суфизм.

\section{Введение}

Концепт факр ققر - добровольная нищета, является одним из основополагающих понятий, которое имеет большое место в развитии концептуальной базы эзотерической системы суфизма (тасаввуф). Некоторые представители суфизма связывают истоки появления и дальнейшего развития данного течения в исламе именно с развитием воззрений концепта факр.

“Факр" арабское слово, означающее бедность, нищету. В толковых словарях арабского, персидско-таджикского, узбекского и турецкого языков слово факр в основном истолковано с точки зрения наличия или отсутствия материального богатства и имеет значения бедный, нищий, неимущий [8. 775; 16. 115; 18. 486; 19. 298; 20. 428]. Усиление и расширение интереса к факру связано с дальнейшим приобретением терминологического значения данного понятия.

В священной книге ислама "Коране" факр объявляется качеством раба (Божьего), а богатство качеством Творца: “Эй люди! Вы нуждаетесь в Боге! Только сам Бог ни от кого не зависит и достоин всех похвал" (“Фотир” сураси, 15-оят) [15. 399].

Истинные факиры по "Корану" познавшие суть существования между страхом Его гнева и надеждой Его благоволенья:

Они свои постели оставляют

И призывают Бога своего

Из страха (гнев Его навлечь),

С надеждой (на Его благоволенье) (32. 16).

В хадисе Пророка Мухаммеда الفقر فخرى) / Aлфакру фахрий ("Нищета моя гордость") факр выражает смысл созвучный с Кораном. В обоих случаях нищета (факр) является предметом гордости из-за того, что он выражает нужду сотворенного в Творце и величие последнего. Навои так выразил это в одном из своих кытъа:

Поя мундин бийик ўлмаски, рисолат хатми,

Факрнинг нисбатида фахрға қилди тасдиқ [4. 513] 


\begin{tabular}{|c|c|c|c|c|c|c|}
\hline \multirow{4}{*}{ Impact Factor: } & ISRA (India) & $=3.117$ & SIS (USA) & $=0.912$ & ICV (Poland) & $=6.630$ \\
\hline & ISI (Dubai, UAE & $=0.829$ & РИНЦ (Russia & $=0.156$ & PIF (India) & $=1.940$ \\
\hline & GIF (Australia) & $=0.564$ & ESJI (KZ) & $=8.716$ & IBI (India) & $=4.260$ \\
\hline & JIF & $=1.500$ & SJIF (Morocce & $=5.667$ & OAJI (USA) & $=0.350$ \\
\hline
\end{tabular}
Пророк

(Степень не может быть выше этого, так как им).

Говоря о факр подтвердил свою гордость

Это воззрение в Коране и Хадисах постепенно стал фундаментом для остановки факру фана в суфизме и факр стал связующим звеном между шари'а и тарика (требованиями ислама и суфийского ордена) [9. 37-38].

В суфизме и суфийской литературе большое внимание удулено факру и он указан как один из основных макамов духовного совершенствования человека. Худжвири приводит слова Шейха Абу Саида Абулхайра: "Факр быть богатым Богом" и истолковывает это как "Целью от этого выражения является осмысление Истины и вечное откровение в ее осмыслении" [24. 26]. В сущности, "вечное откровение" в суфизме служил для решения проблем, связанных с проблемами обретения человеком духовно-нравственного совершенства. А также, суждениям на тему факр можно столкнуться и в изречениях других представителей суфизма. В частности, в хикматах Ахмада Йасави он находит следующее воплощение:

Ишқ подшох, ошиқ фақир дам уролмас,

Хақдин рухсат бўлмагунча сўзлай олмас [25. 42].

(Любовь - царь, влюбленный - факир, молчание его удел

Пока не будет изволение от Бога)

Факр, по представлению Йасави, качество влюбленного, а лбовь - царь. Точно так же, как простой подданный не может вымолвить слово в присутствии у царя, влюбленный не может свободно говорить во владении божественной любви. А чтобы говрить нужно разрешение Бога. Значит, воля факира-влюбленного полностью подчинена воле Бога.

Пожалуй нет ни одного большого поэта Востока, который бы не писал о факр. Одним из таких художников является Джалаладдин Руми. В его стихах понятие факр интерпретировано на основе суфийской доктрины. Он утверждает, что факр это такая высшая стоянка в суфизме, которую многие старались достичь, но это удалось только немногим:

Ба рохе факр бисёре давиданд,

Ба манзилгох вале камтар расиданд [17. 149].

(Многие бегали по пути факр,

Но цели достигли немногие)

Утверждение крупного представителя суфийского ордена хваджаган-накшбандиййа Бахоуддина Накшбанда: "Всего, что мы достигли на этом пути (на пути суфизма - H.P.) достигли благодаря факр" [2. 54], имело под собой логичное основание. В некоторых работах указывается, что Бахоуддин Накшбанд для полного следования жизненным принципам Пророка Мухаммада фундаментом своего учения выбрал факр [10. 214]. Следует особо указать, что в связи с влиянием ордена накшбандия широкая интерпретация концепта факр вышло на новый, более высокий уровень как в персидскотаджикской литературе, так и в литературе тюркских народов. Две выдающиеся мастера слова - поэзия Абдурахмана Джами и Алишера Навои могут послужить ярким потверждением данного утверждения. В творчестве этих поэтов факр выступает не только как важная идея, но и как многогранный образ.

Вопрос интерпретации концепта факр в поэзии Навои была изучена в некоторой степени [1. 57-77; 11. 61; 12. 49-50; 13. 10-28; 21:243; 22. 139; 23. 71-86], но данная проблема не становилась объектом широкого специального исследования в навоиведении.

В 123 произведениях 5 лирических жанров сборника диванов "Хазоин ул-маони", в частности, в 113 газелях, 3 рубаи, 4 кытъа, 1 мухаммасе, 2 саки-наме дается всесторонняя интерпретация концепта факр и создан образ факира - одного из сложных и многогранных лирических образов восточной литературы.

По мнению Навои понятие факр включает в себя ряд качеств, без которых немыслимо достижение человеком совершенства. Путь влюбленного, томящегося в разлуке, к своей возлюбленной лежит через факр и здесь его мало волнуют такие понятия, как учмог (рай), томуг (ад), сирот (мост в рай над адом). Все его мысли обращены к Возлюбленной:

Васлға йўл хажрдин факр ўлди кўргил турфаким,

Бирдин учмоғдур хижил, бирдин томуғ, бирдин сирот [3. 231].

(Посмотри, как путь от разлуки к свиданию (с возлюбленной) лежит через факр, cupom)

И здесь (влюбленного) мало волнуют рай, ад,

Но Навои подчеркивает, что путь факр тернист, который полон разных психологических препятствий, трудностей и мучений, поэтому прежде чем вступить на этот путь надо выбрать "знатока пути" - "путеводителя":

Ўз бошинг ила куйма қадам факр йўлиға,

Топмағуча бу мархаланинг рохшуносин [4. 341].

(Сам по себе не вступай на путь факр,

Пока не найдешь путеводителя этой дороги)

Иначе не будет никакого результата. В этой связи хотим уделить внимание на один факт. Навои в своей онтологии поэтов "Маджалис уннафаис" говоря о поэте Бинаи пишет о том, что он в целях искоренения тщеславия в своем характере предпринял попытку вступить в путь факр, но так как у него не было наставника он не достиг никаких результатов: “Но так как был тщеславен 


\begin{tabular}{|c|c|c|c|c|c|c|}
\hline \multirow{4}{*}{ Impact Factor: } & ISRA (India) & $=3.117$ & SIS (USA) & $=0.912$ & ICV (Poland) & $=6.630$ \\
\hline & ISI (Dubai, UAI & $=0.829$ & РИНЦ (Russia & $=0.156$ & PIF (India) & $=1.940$ \\
\hline & GIF (Australia) & $=0.564$ & ESJI (KZ) & $=8.716$ & IBI (India) & $=4.260$ \\
\hline & JIF & $=1.500$ & SJIF (Morocco & $=5.667$ & OAJI (USA) & $=0.350$ \\
\hline
\end{tabular}

и обладал гордыней сообщество его не приняло. Для искоренения этого качества вступил в путь факр и даже прошел испытание мученичеством, но так как у него не было наставника и путеводителя (пир и муршид - Н.Р.) и был самоучкой никакой пользы не получил" [7. 74].

Согласно интерпретации Навои человек, вступивший в путь факр должен отречься, освободиться от желаний своей плоти, препятствующих достижения истинной цели. Потому что "Я” - занавес, препятствие на пути к Истине:

Фақр водийсиға кирган ташласун ўзлук юкин

Ким, қилур йўл қатъин осонроқ неча бўлғай енгил [4. 273].

(Вступивший на путь факр должен выбросить ношу собственного "Я",

Тот быстрее преодолеет этот путь кто более легок)

Существенное место в лирике Навои занимает вопрос очищения души, ее совершенствования посредством факр. Ибо, следование требованиям плоти унижает человека, а жизнь согласно требованиям факр, наоборот, возвеличивает: бирла,

Нафс хор этмиш Навоийни азиз эт факр

Эй жалолу рахматингдин гар залилу гар муаззаз [4. 146].

(Плотские желания унизили Навои, возвеличь его факром,

Снизошли ему благодать, является ли он падшим или почитаемым)

В некоторых источниках утверждается, что причиной возвеличивания факр является то, что он является своеобразным замком, охраняющим искателя истины от разного рода невзгод. Снаружи (захир) факир хотя и смотрится нелицеприятно, но изнутри (батин) полон божественного света.

По мнению Навои богатства этого мира, а главное любовь к ним уничтожают принципы факр в человеческой душе. Как известно, богатства этого мира ограничены как в количественном, так и в пространственном отношении. Душа стремящаяся к безграничности выбирает только безграничное богатство богатство факр. Только это богатство является поистине безграничным и дух стремящееся к свободе может освободиться от тесных границ этого мира овладев богатством факр:

Эй Навоий, давлати зохирни доим топмоғунг, [4. 265].

Фақр иқболидурур, улким давоми бор анинг

(O, Навои, не всегда можно найти богатство внешнего мира,

Преимуществом факра является то, что оно безграничное)
Богатство сегодня есть, завтра его нет. В нем отсутствует качество постоянности. Сегодня улыбается тебе, завтра другому. Сегодня им распоряжаешься ты, завтра другой. Путем спасения от непостоянства этого мира, уберечь свое душевное равновесение, психическое состояние, не поддаваться его негативному воздействию - является факр.

Порвать посредством факр нити соединяющие с этим миром и ведет влюбленного к истинному счастью - к Истине. Иметь отношения с тленным миром тяжелая ноша на пути факр. Нити, соединящие человека с миром покоятся в его душе. Поэтому лирический герой обращается к своей душе и призывает отречься от принадлежности (та'аллук) и обратиться к факр:

Фақр йўлинда оғирроқ юк эрур вобасталиқ,

Эй кўнгул, тарки тааллуқ айлабон, ул сори бор [5. 110].

(Тяжелой ношей является свзянность на пути факр,

О, душа, покинь принадлежность (к миру сему) и иди к Нему!)

Согласно преданию легендарный царь Джамшид заказал ученым две чаши для вина. Одна из них чаша (имратфизой), вино в которой никогда не кончается, сколько бы из нее не пили. Вторая чаша (гитийнамой), которая показывает все, что происходит в этом мире. Как предание гласит, Джамшид посредством этиш чаш был в курсе всего, что происходит в мире и занимал особое положение среди царей. Навои глиняный сосуд (сафол) факр сравнивает с чашей Джамшида (Жоми Жам) и первое ставит выше последнего:

Сафоли фақр ол, жону жахон нақдин бериб, гарчи

Киши Жамшид жомин сотқин олмайдур, бахо айлаб [5. 47].

(Приобретай глиняный сосуд факр, если для этого придется отдать даже душу и все богатства этого мира, хотя

Человек не сможет купить чашу Джамшида за любую цену)

Если в вышеприведенном примере Навои ставит на один ряд чашу Джамшида и глиняный сосуд факр, то в другом месте ставит его выше чаши Джамшида:

Жоми Жамнинг рохи Афридун йилони захридур, [6. 262].

Эй кўнгул, ўзни сафоли фақр ила хурсанд қил

(Вино из под чаши Джамшида не более чем яд змеи Фаридуна, факр)

О душа, увесели себя глиняным сосудом

То есть, вино с чаши Джамшида не более чем яд змеи легендарного царя Фаридуна, о душа, если ты действительно хочешь истинного наслаждения 


\begin{tabular}{|c|c|c|c|c|c|c|}
\hline \multirow{4}{*}{ Impact Factor: } & ISRA (India) & $=3.117$ & SIS (USA) & $=0.912$ & ICV (Poland) & $=6.630$ \\
\hline & ISI (Dubai, UAE & $=0.829$ & РИНЦ (Russia) & $=0.156$ & PIF (India) & $=1.940$ \\
\hline & GIF (Australia) & $=0.564$ & ESJI (KZ) & $=8.716$ & IBI (India) & $=4.260$ \\
\hline & JIF & $=1.500$ & SJIF (Morocco) & $=5.667$ & OAJI (USA) & $=0.350$ \\
\hline
\end{tabular}

от божественного вина увесели себя вином из под глиняного сосуда факр.

Один из представителей суфизма сказал: "Путей, приводящих адепта к Богу было больше чем звезд на небе. Теперь из тех путей остался только факр, ибо и самым верным путем является он" [14. 445]. Значит, путь факр был таким верным, что Бог “видел народ посредством факиров, из-за уважения к ним и благодаря их благочестивости увеличивал их пропитание (ризк)" [14. 440].

Главным подспорьем достижения факиром расположения Бога является то, что он обладатель абсолютной искренности. Он в чистоте своих помыслов достиг такого уровня, что он освободился от чувства нужды даже от Бога. Лирический герой Алишера Навои тоже мечтает о такой судьбе:
Эхтиёжимни улустин уз, Худоё, фақр ила, [6. 71].

Уйла фақрким, анга бўлмас Худога эхтиёж

(О боже! Порви мою потребность в людях посредством факр, Боге!)

Таким факром в котором не будет нужды в

Почему не остается нужда в Боге? Потому что для факира нет надобности искать истину извне, он достиг состояния единения с Богом.

Итак, посредством интерпретации концепта факр и создания образа факира Алишер Навои с большим мастерством выдвигал свои наиболее важные общественно-политические, философские, религиозно-суфийские идеи и воззрения.

\section{References:}

1. Abduқodirov, А. (1995). Navoiy va vax̧dat ulvuzhud ta"limoti. Khy̆zhand.

2. Abulmuxsin Muxammad Воқir ibn Muxammad Ali. (1993). Bax̧ouddin Balogardon. Toshkent.

3. Navoiy, A. (1988). Khazoyin ul-maoniy. Faroyib us-siғar. Mukammal asarlar ty̆plami: 20 tomlik. 3-tom. Toshkent.

4. Navoiy, A. (1989). Khazoyin ul-maoniy. Navodir ush-shabob. Mukammal asarlar ty̆plami: 20 tomlik. 4-tom. Toshkent.

5. Navoiy, A. (1990). Khazoyin ul-maoniy. Badoe" ul-vasat. Mukammal asarlar ty̆plami: 20 tomlik. 5-tom. Toshkent.

6. Navoiy, A. (1990). Khazoyin ul-maoniy. Favoyid ul-kibar. Mukammal asarlar ty̆plami: 20 tomlik. 6-tom. Toshkent.

7. Navoiy, A. (1966). Mazholis un-nafois. Asarlar. 15 tomlik. 12-tom. Toshkent.

8. (1957). Arabsko-russkiy slovar'. Moscow.

9. Bertel's, E. E. (1965). Sufizm i sufiyskaya literatura. Izbr. trudy. Tom 3. M.

10. Bertel's, E. E. (1965). Navoi i Dzhami. Izbr. trudy. Tom 4. M.

11. Isхоқоv, E. (1965). Alisher Navoiyning ilk lirikasi. Toshkent.
12. Ізхоқоv, Е. (1983). Navoiy poetikasi. Toshkent.

13. Komilov, N. (1993). Ikki xadis orasi / Zhaxon mulkining nigoxboni. Bukhoro.

14. Kuşeyri, A. (1991). Risale'i Kuşeyri. Istanbul.

15. Kur"oni, K. (1992). Tarzhima va izox̧lar muallifi A. Mansur. Toshkent.

16. Fiesiddin, M. (1988). Fies ul-luzot. 1-tom. Dushanbe.

17. Rumӣ, Ч.. (1992). Devoni kabir. Dushanbe.

18. (1988). Türkçe sözlük. Ankara.

19. (1981). Y̌zbek tilining izoxli luғati. 2-tom. M.

20. (1969). Farxangi zaboni toчikū. Tom 2. M.

21. Xayitmetov, A. (1961). Navoiy lirikasi. Toshkent.

22. Xayitmetov, A. (1993). Navoiykhonlik suxbatlari. Toshkent.

23. Хаққиl I. (1991). Tasavvuf va she"riyat. Toshkent.

24. Khudzhviri, Abulkhasan Ali ibn Usman. (1926). Kashf ul-makhdzhub li arbob il-kulub. Persidskiy tekst, primechaniya i ukazateli V.A.Zhukovskogo. - L.

25. Yassaviy, K. A. (1992). Devoni x̧ikmat. Toshkent. 